\title{
Resistance against Carbon Deposition via Controlling Spatial Distance of Catalytic Components in Methane Dehydroaromatization
}

\author{
Yan Zeng ${ }^{1}$, Ayano Kimura ${ }^{1}$, Peipei Zhang ${ }^{1, *}$, Jiaming Liang ${ }^{1}$, Jiaqi Fan ${ }^{1}$, Liwei Xiao ${ }^{1}$, Chengwei Wang ${ }^{1}$, \\ Guohui Yang ${ }^{1,2}$, Xiaobo Peng ${ }^{1, * \mathbb{D}}$ and Noritatsu Tsubaki ${ }^{1, *}$ \\ 1 Department of Applied Chemistry, School of Engineering, University of Toyama, 3190 Gofuku, \\ Toyama 930-8555, Japan; d1878105@ems.u-toyama.ac.jp (Y.Z.); m1971410@ems.u-toyama.ac.jp (A.K.); \\ m1971422@ems.u-toyama.ac.jp (J.L.); m2071424@ems.u-toyama.ac.jp (J.F.); \\ m2071423@ems.u-toyama.ac.jp (L.X.); m2071422@ems.u-toyama.ac.jp (C.W.); \\ thomas@eng.u-toyama.ac.jp (G.Y.) \\ 2 State Key Laboratory of Coal Conversion, Institute of Coal Chemistry, Chinese Academy of Sciences, \\ Taiyuan 030001, China \\ * Correspondence: zhangpp@eng.u-toyama.ac.jp (P.Z.); pengxb@eng.u-toyama.ac.jp (X.P.); \\ tsubaki@eng.u-toyama.ac.jp (N.T.); Tel.: +81-076-445-6848 (N.T.)
}

check for updates

Citation: Zeng, Y.; Kimura, A.; Zhang, P.; Liang, J.; Fan, J.; Xiao, L.; Wang, C.; Yang, G.; Peng, X.; Tsubaki, N. Resistance against Carbon Deposition via Controlling Spatial Distance of Catalytic Components in Methane Dehydroaromatization. Catalysts 2021, 11, 148 https://doi.org/10.3390/catal11020148

Received: 22 December 2020

Accepted: 18 January 2021

Published: 21 January 2021

Publisher's Note: MDPI stays neutral with regard to jurisdictional claims in published maps and institutional affiliations.

Copyright: (c) 2021 by the authors. Licensee MDPI, Basel, Switzerland. This article is an open access article distributed under the terms and conditions of the Creative Commons Attribution (CC BY) license (https:/ / creativecommons.org/licenses/by/ $4.0 /)$

\begin{abstract}
Molybdenum-zeolite catalysts always suffer from severe carbon deposition and rapid deactivation in the methane dehydroaromatization (MDA) process. Herein, we present a strategy that controls spatial distance between Mo species and HMCM-22 zeolite over Mo/HMCM-22 catalysts, to inhibit the severe carbon deposition. Our characterization analyses demonstrate that the Mo/HMCM-22 catalysts possess the same active components, but the spatial distance plays a key role in determining product selectivity in the MDA process. The MDA performance reveals that Mo/HMCM-22-MM (mechanical milling) catalyst, with a medium spatial distance between Mo species and HMCM-22 zeolite, significantly inhibits carbon deposition and produces high selectivity to benzene. This work shows that spatial distance between molybdenum and zeolite is an important property for suppressing carbon deposition and improving benzene selectivity in MDA process.
\end{abstract}

Keywords: spatial distance; molybdenum; HMCM-22; carbon deposition; methane dehydroaromatization

\section{Introduction}

Methane is the main component of natural gas, shale gas, flammable ice, etc. In recent years, conversion of methane into high value-added chemicals has attracted widespread attention [1,2]. To produce target products, direct and indirect syntheses have also been extensively explored in methane conversion. The direct synthesis usually utilizes a reaction process (such as oxidation, chlorination, or dehydroaromatization) to directly convert methane into desired products [3-9]. The indirect synthesis involves syngas $\left(\mathrm{CO} / \mathrm{H}_{2}\right)$ production from methane, and conversion of the syngas into methanol, dimethyl ether, liquid fuels, and so on [10-13]. In comparison, the direct synthesis would be a more promising strategy to minimize production costs in the future. Moreover, there is a great need to further develop and optimize the direct synthesis for enhancing the efficiency of methane utilization.

Benzene is a very important basic material in the chemical industry. Direct synthesis of benzene from methane, i.e., methane dehydroaromatization (MDA), can enhance the utilization of natural gas, shale gas, flammable ice, etc. To realize the direct synthesis of benzene, Mo-based zeolites (for instance, Mo/HZSM-5 and Mo/HMCM-22) are wellrecognized catalysts [7,14-16]. The Mo species is a catalytic component for methane activation to produce reaction intermediates, and Brønsted acid from the zeolites is another 
active component for subsequent aromatization of the intermediates [16,17]. Although in the MDA process methane conversion is limited by thermodynamic equilibrium, high selectivity of the benzene product can be obtained $[16,18]$. In contrast, severe carbon deposition and rapid deactivation are the most serious problems for Mo-based zeolites in the MDA process [16-19]. Therefore, it is highly desirable to develop new catalytic designs for the Mo-based zeolites to inhibit carbon deposition and deactivation.

The spatial distance of active components is an important parameter for catalyst designs. In our previous works, we prepared a series of core-shell catalysts for Fischer-Tropsch synthesis, dimethyl ether synthesis, etc. [20,21]. The active components with different catalytic functions were distributed in the core and shell, respectively. The shell thickness and core diameter were two key factors to determine the product distribution [22,23]. In addition, bifunctional catalysts, composed of metal oxide and zeolites, have been widely studied on hydrogenation of $\mathrm{CO}$ or $\mathrm{CO}_{2}$ to light olefins and aromatics [24-28]. The changes of spatial distance and distribution, between the metal oxide and zeolites, also remarkably influenced the product selectivity. Therefore, it is worth trying to control spatial distance of the Mo species and Brønsted acid centers in the MDA process, for improving the catalytic performance and suppressing the heavy carbon deposition.

Herein, we report that the spatial distance of the Mo species and Brønsted acid centers, over Mo/HMCM-22 catalysts, is tuned for high resistance of carbon deposition in the MDA process. Multiple methods and strategies (including hydrothermal synthesis (HS), wet impregnation (WI), mechanical milling (MM), physical mixing (PM), and dual catalytic beds (DCB) (see the experimental section and Figure 1 for details) are employed to control the spatial distance of the two active components. The MDA performance reveals that the Mo/HMCM-22-MM catalyst, prepared from the mechanical milling, which is a type of mechanochemical activation (MCA), exhibits superior catalytic activity and benzene selectivity, and significantly inhibits carbon deposition. The high resistance of carbon deposition, over the Mo/HMCM-22-MM catalyst, is ultimately attributed to a suitable spatial distance of Mo species and HMCM-22 zeolite. It can produce a strong synergy between methane conversion and aromatization of the intermediates, to suppress carbon deposition during the MDA process.

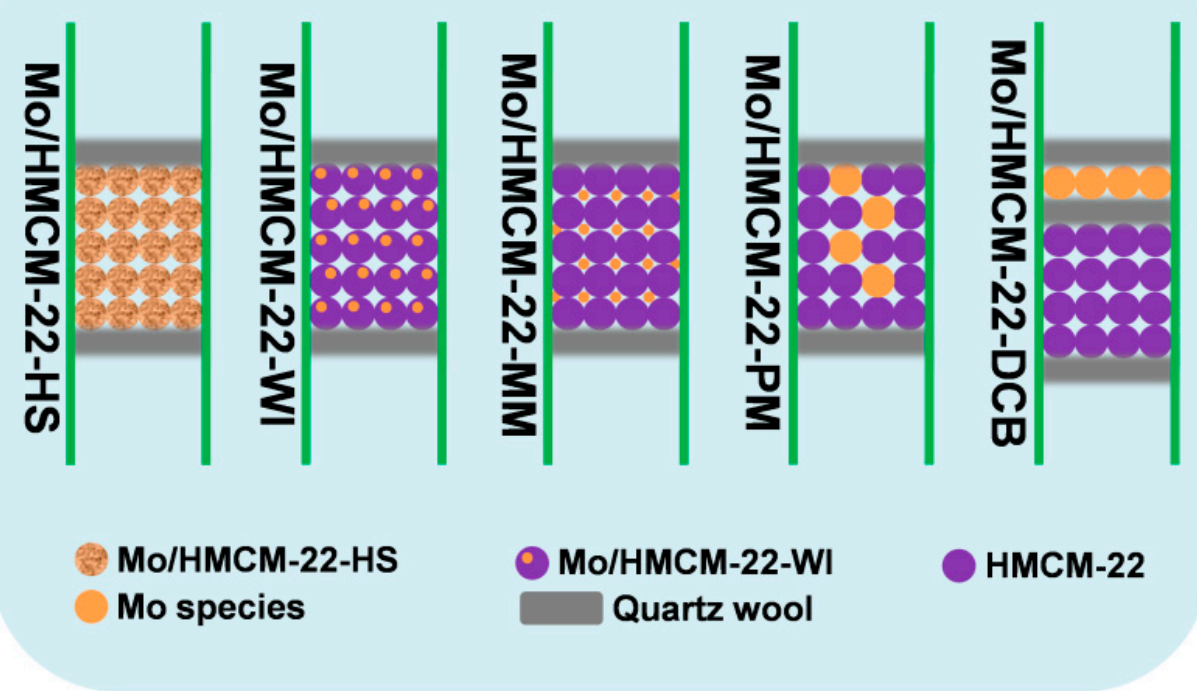

Figure 1. Schematic diagrams of the Mo/HMCM-22 catalysts with different spatial distances of Mo species and HMCM-22 zeolite. The diagrams from left to right: Mo/HMCM-22-HS, Mo/HMCM22-WI, Mo/HMCM-22-MM, Mo/HMCM-22-PM, and Mo/HMCM-22-DCB. These abbreviations correspond to hydrothermal synthesis (HS), wet impregnation (WI), mechanical milling (MM), physical mixing (PM), and dual catalytic beds (DCB), respectively. 


\section{Results and Discussions}

\subsection{Structural Characterization}

The schematic diagrams of Mo/HMCM-22 catalysts are shown in Figure 1. The diagrams from left to right correspond to the Mo/HMCM-22-HS, Mo/HMCM-22-WI, $\mathrm{Mo} / \mathrm{HMCM}-22-\mathrm{MM}$, Mo/HMCM-22-PM and Mo/HMCM-22-DCB, respectively. On these Mo/HMCM-22 catalysts, we designed different spatial distributions to gradually expand the distances of the Mo species and Brønsted acid centers. As indicated in Table S1, the average distances between the Mo species and Brønsted acid centers were revealed, and changed from $9.0 \times 10^{-3}$ to $1.5 \times 10^{4} \mu \mathrm{m}$ for these Mo/HMCM-22 catalysts. In addition, in the MDA process, porous structures and acidic properties of these Mo/HMCM-22 catalysts were also two important factors in determining the MDA performance. Therefore, to reveal the porous structures and acid properties, we employed multiple characterization techniques to analyze the structural and chemical features for these Mo/HMCM-22 catalysts.

The XRD analysis was utilized to investigate the crystal structures of Mo/HMCM22 catalysts. Pure $\mathrm{MoO}_{3}$ and $\mathrm{HMCM}-22$ zeolite were employed as reference samples in the analysis. As shown in Figure 2, the Mo/HMCM-22-HS, Mo/HMCM-22-WI and Mo/HMCM-22-MM exhibited the same diffraction patterns as that of the HMCM-22 zeolite, indicating similar zeolite structures. Moreover, we did not observe the characteristic peaks of $\mathrm{MoO}_{3}$ on these Mo/HMCM-22 catalysts. This suggests that the HMCM-22 zeolite was the main structure for these $\mathrm{Mo} / \mathrm{HMCM}-22$ catalysts, and the $\mathrm{MoO}_{3}$ species was highly dispersed on them.

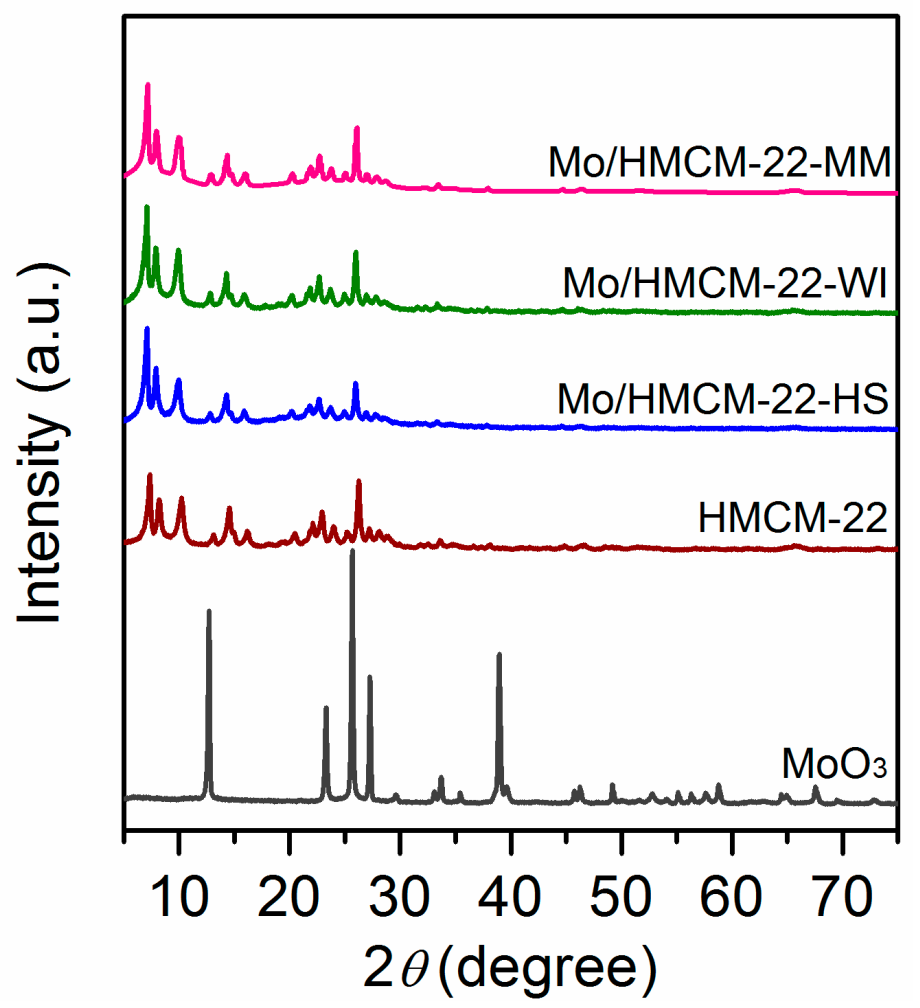

Figure 2. X-ray diffraction (XRD) patterns of $\mathrm{MoO}_{3}, \mathrm{HMCM}-22$ zeolite and various $\mathrm{Mo} / \mathrm{HMCM}-22$ catalysts.

We further utilized scanning electron microscopy (SEM) analysis to observe surface morphology for the pure HMCM-22 zeolite and Mo/HMCM-22 catalysts as in Figure 3. The results revealed that the pure HMCM-22 zeolite generated a uniform shape and size for the zeolite particles. However, the Mo/HMCM-22-HS, Mo/HMCM-22-WI and Mo/HMCM-22-MM catalysts gradually changed the particle shapes and decreased the 
particle sizes. We further counted the thickness of these three samples as in Figure S1. The average sheet thickness of Mo/HMCM-22-HS, Mo/HMCM-22-WI and Mo/HMCM-22MM was about $0.118,0.111$, and $0.107 \mu \mathrm{m}$, respectively. To our knowledge, the smaller particles of HMCM-22 zeolite can generate higher utilization efficiency for the Brønsted acid centers, because acidic sites inside the zeolite crystals are more accessible by reactants.
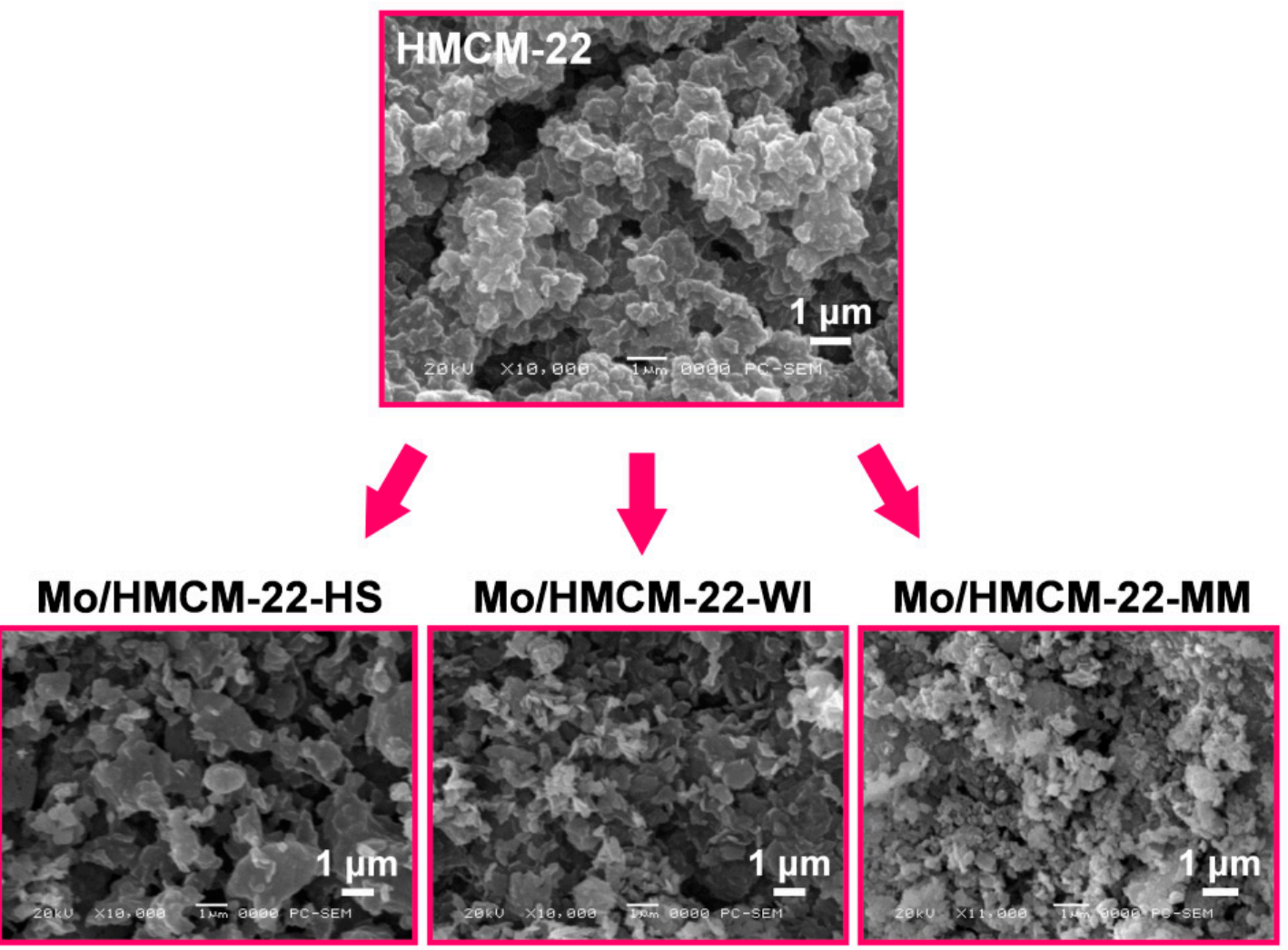

Figure 3. Scanning electron microscopy (SEM) images for the HMCM-22 zeolite and Mo/HMCM-22 catalysts. (top) HMCM22 zeolite, (bottom left) Mo/HMCM-22-HS, (bottom center) Mo/HMCM-22-WI, and (bottom right) Mo/HMCM-22-MM.

The Mo contents and $\mathrm{Si} / \mathrm{Al}$ ratios of $\mathrm{Mo} / \mathrm{HMCM}-22$ catalysts were measured by EDS $[29,30]$ and X-ray fluorescence (XRF) analyses. The results in Table 1 show that the Mo contents were around $6 \mathrm{wt} \%$ and the $\mathrm{Si} / \mathrm{Al}$ ratios were about 20 for all the Mo/HMCM-22 catalysts. In addition, we employed $\mathrm{N}_{2}$ physisorption to investigate textural properties for the Mo/HMCM-22 catalysts. As indicated in Figure 4, the Mo/HMCM-22 catalysts and pure HMCM-22 zeolite exhibit similar hysteresis loops for $\mathrm{N}_{2}$ adsorption-desorption isotherms. Moreover, they also display similar total volume $\left(\mathrm{V}_{\text {total }}\right)$, micropore volume $\left(\mathrm{V}_{\text {micro }}\right)$ and mesopore volume $\left(\mathrm{V}_{\text {meso }}\right)$, respectively, as in Table $\mathrm{S} 2$. Although BET surface areas $\left(\mathrm{S}_{\mathrm{BET}}\right)$ were different on these samples, the similar pore structures revealed that shape selective functions towards aromatics were not changed on the Mo/HMCM-22 catalysts.

The $\mathrm{H}_{2}$-TPR results are compared in Figure 5. The Mo/HMCM-22-WI exhibit three main peaks for its TPR profile. The first peak at $460{ }^{\circ} \mathrm{C}$ was attributed to reduction of $\mathrm{MoO}_{3}$ to $\mathrm{MoO}_{2}$ [31,32]. The second peak at $570{ }^{\circ} \mathrm{C}$ was caused by strong interaction between the $\mathrm{MoO}_{3}$ species and HMCM-22 zeolite. The third peak at $710^{\circ} \mathrm{C}$ was due to further reduction of the $\mathrm{MoO}_{2}$ species [33,34]. In comparison to the Mo/HMCM-22-WI, the Mo/HMCM-22HS generated a very low intensity for the $\mathrm{H}_{2}$-TPR peaks. This demonstrated that it was difficult to activate the Mo species inside the Mo/HMCM-22-HS. Unlike the Mo/HMCM22-WI and Mo/HMCM-22-HS, the Mo/HMCM-22-MM only showed a broad peak at a temperature range from 400 to $700{ }^{\circ} \mathrm{C}$. This observation suggests that the preparation method of mechanical milling not only controlled the distance between the Mo species 
and HMCM-22 zeolite, but also significantly improved the ability for reduction of the Mo species.

Table 1. Si / Al ratios and Mo contents for the HMCM-22 zeolite and Mo/HMCM-22 catalysts.

\begin{tabular}{|c|c|c|}
\hline Sample & Mo Content $(w t \%)^{a}$ & Si/Al Ratio ${ }^{b}$ \\
\hline HMCM-22 & / & 20 \\
\hline Mo/H-MCM-22-HS & 5.8 & 23 \\
\hline Mo/HMCM-22-WI & 6.4 & 21 \\
\hline Mo/HMCM-22-MM & 6.3 & 21 \\
\hline Mo/HMCM-22-PM ${ }^{\mathrm{c}}$ & 6.0 & 20 \\
\hline $\mathrm{Mo} / \mathrm{HMCM}-22-\mathrm{DCB}^{\mathrm{c}}$ & 6.0 & 20 \\
\hline
\end{tabular}

a Mo contents were measured by EDS analysis; ${ }^{\mathrm{b}}$ the $\mathrm{Si} / \mathrm{Al}$ ratios were obtained from X-ray fluorescence (XRF) analysis; ${ }^{\mathrm{c}}$ the $\mathrm{Si} / \mathrm{Al}$ ratios and Mo contents were calculated according to the amount of raw materials.

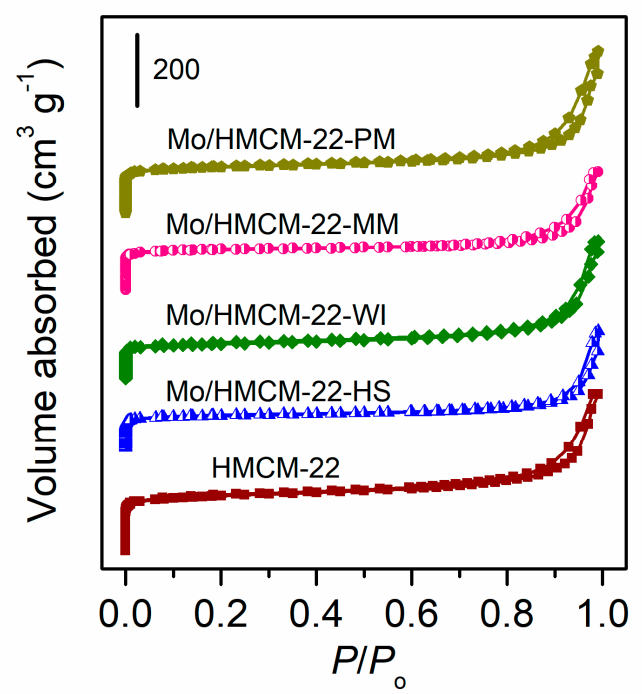

Figure 4. $\mathrm{N}_{2}$ adsorption-desorption isotherms for the HMCM-22 zeolite and various Mo/HMCM-22 catalysts.

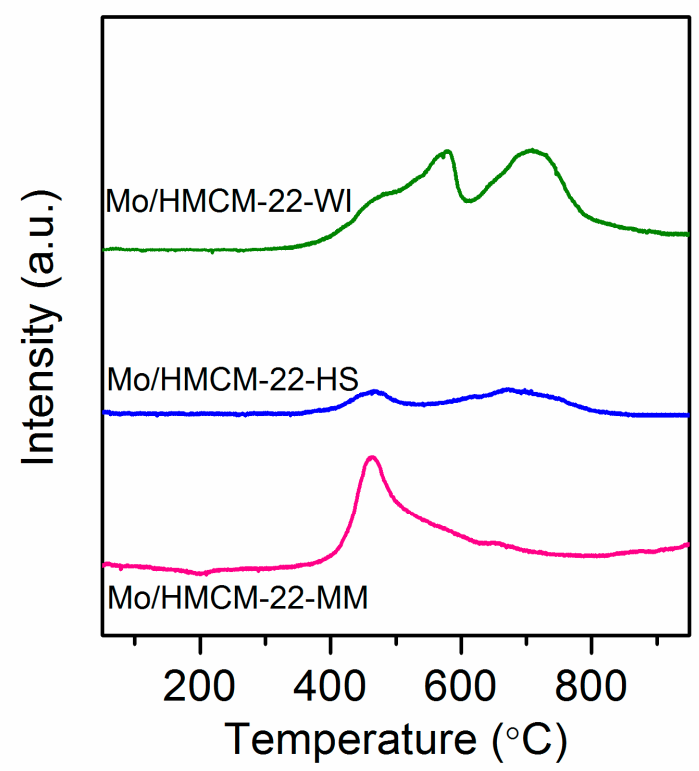

Figure 5. $\mathrm{H}_{2}$-TPR profiles for the Mo/HMCM-22-HS, Mo/HMCM-22-WI and Mo/HMCM-22-MM catalysts. 
To elucidate the acidic properties, we performed $\mathrm{NH}_{3}$-TPD analyses for the HMCM-22 zeolite, Mo/HMCM-22-WI and Mo/HMCM-22-MM samples as in Figure 6. On these samples, two peaks are observed in the $\mathrm{NH}_{3}$-TPD profiles. The low-temperature peak at $180{ }^{\circ} \mathrm{C}$ was attributed to physical adsorption of $\mathrm{NH}_{3}$ molecules, and weak interaction between $\mathrm{NH}_{3}$ molecules and weak acid centers. The high-temperature peak at $400{ }^{\circ} \mathrm{C}$ was ascribed to strong interaction between $\mathrm{NH}_{3}$ molecules and Brønsted acid centers [35,36]. The pure HMCM-22 zeolite exhibited higher intensity for the high-temperature peak than the Mo/HMCM-22-WI and Mo/HMCM-22-MM catalysts. Moreover, the TPD profile of the HMCM-22 zeolite was the same as that of Mo/HMCM-22-HS catalyst as in Figure S2. In particular, Mo/HMCM-22-WI and Mo/HMCM-22-MM catalysts formed similar $\mathrm{NH}_{3}$-TPD profiles. This demonstrated that these two samples generated similar acidic properties. The similar acidic properties further indicate that they should possess the same ability for aromatization of the intermediates to benzene product in MDA process.

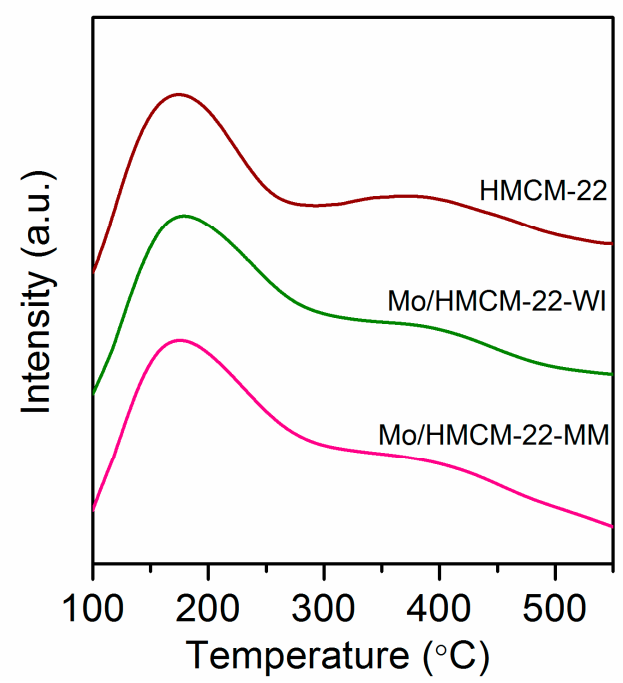

Figure 6. $\mathrm{NH}_{3}-\mathrm{TPD}$ analyses for the HMCM-22, Mo/HMCM-22-WI and Mo/HMCM-22-MM samples.

We further employed XPS analysis to investigate surface chemical states for $\mathrm{MoO}_{3}$, $\mathrm{Mo} / \mathrm{HMCM}-22-\mathrm{WI}$ and Mo/HMCM-22-MM samples as in Figure 7. The Mo $3 \mathrm{~d}$ region is displayed in Figure 7a. The pure $\mathrm{MoO}_{3}$ sample exhibits two photoelectron peaks at binding energies of 232.9 and $236.1 \mathrm{eV}$. They should correspond to $3 \mathrm{~d} 5 / 2$ and $3 \mathrm{~d} 3 / 2$ core levels for molybdenum oxide $\left(\mathrm{Mo}^{6+}\right)$, respectively $[37,38]$. The Mo/HMCM-22-WI and Mo/HMCM22-MM catalysts display lower binding energies for the characteristic peaks of the Mo 3d region, as compared to the pure $\mathrm{MoO}_{3}$ sample. This is due to the fact that low oxidation state of molybdenum oxide was formed on these two samples. Especially, the Mo/HMCM22-WI and Mo/HMCM-22-MM samples also showed a similar Mo $3 \mathrm{~d}$ spectrum. It suggests that they possessed the same surface chemical states for Mo species. In addition, the $\mathrm{O} 1 \mathrm{~s}$ region is displayed in Figure $7 \mathrm{~b}$. The peak at binding energy of $530.9 \mathrm{eV}$ was attributed to O1s for pure $\mathrm{MoO}_{3}$, and the peak at binding energy of $531.3 \mathrm{eV}$ was assigned to $\mathrm{O} 1 \mathrm{~s}$ for HMCM-22 zeolite [39-41]. The O 1s spectra also uncovered that the Mo/HMCM-22-WI and $\mathrm{Mo} / \mathrm{HMCM}-22-\mathrm{MM}$ formed similar $\mathrm{O}$ species. In addition to the Mo $3 \mathrm{~d}$ and $\mathrm{O} 1 \mathrm{~s}$ regions, the $\mathrm{Si} 2 \mathrm{p}$ and $\mathrm{Al} 2 \mathrm{p}$ regions further demonstrated that the Mo/HMCM-22-WI and Mo/HMCM-22-MM catalysts also generated the same surface chemical states for $\mathrm{Si}$ and $\mathrm{Al}$ species as in Figure 7c,d. Thus, we confirmed that the Mo/HMCM-22-WI and $\mathrm{Mo} / \mathrm{HMCM}-22-\mathrm{MM}$ catalysts provided the same surface chemical states of $\mathrm{Mo}, \mathrm{O}, \mathrm{Si}$, and $\mathrm{Al}$ species for MDA process. 
(a)

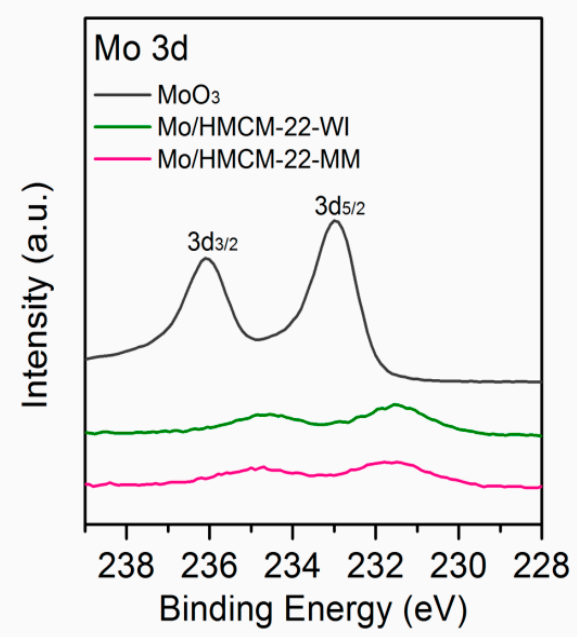

(c)

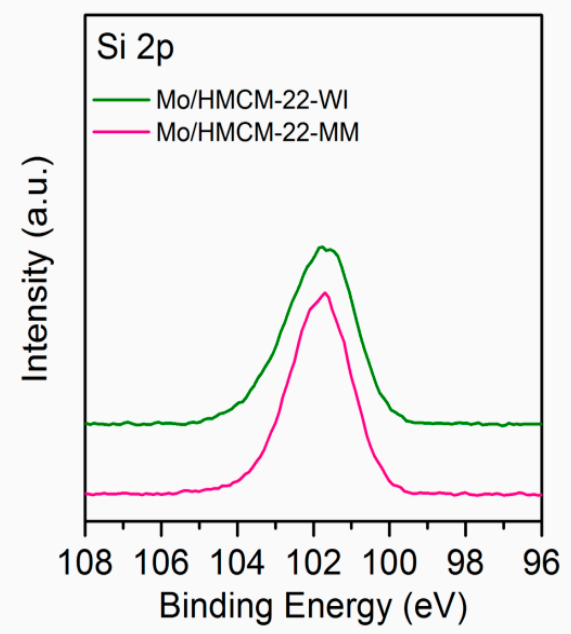

(b)

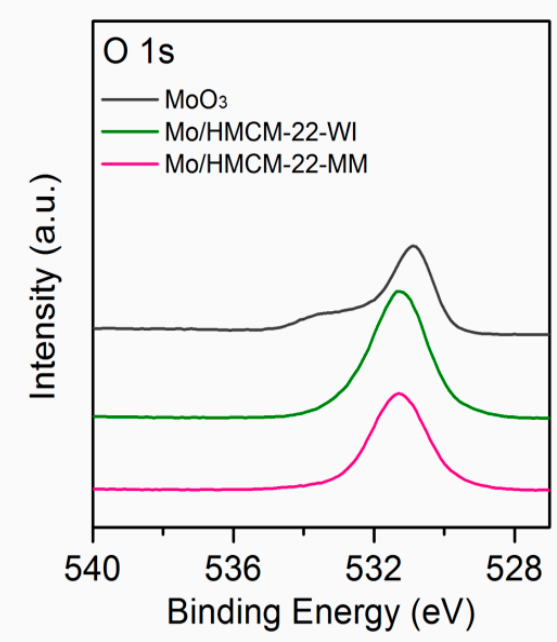

(d)

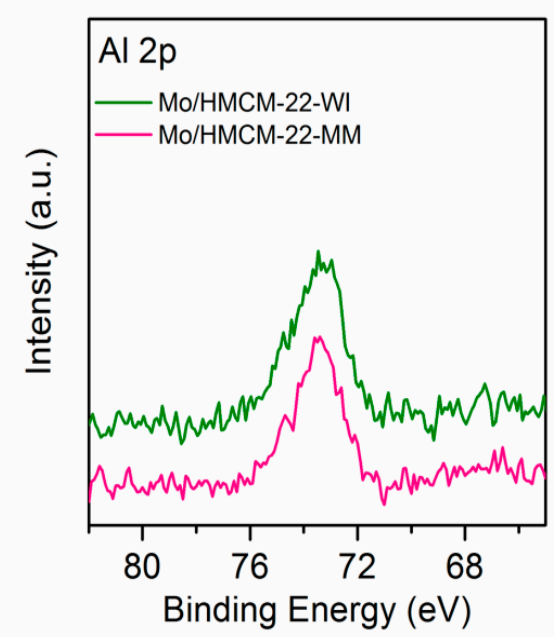

Figure 7. XPS analysis of the $\mathrm{MoO}_{3}$, Mo/HMCM-22-WI and Mo/HMCM-22-MM samples. (a) Mo $3 \mathrm{~d}$ region for the $\mathrm{MoO}_{3}, \mathrm{Mo} / \mathrm{HMCM}-22-\mathrm{WI}$ and Mo/HMCM-22-MM; (b) O 1s region for the $\mathrm{MoO}_{3}, \mathrm{Mo} / \mathrm{HMCM}-22-\mathrm{WI}$ and Mo/HMCM-22-MM; (c) Si 2p region for the Mo/HMCM-22-WI and Mo/HMCM-22-MM and (d) Al 2p region for the Mo/HMCM-22-WI and Mo/HMCM-22-MM.

\subsection{MDA Performance}

To evaluate the MDA performance, we tested the Mo/HMCM-22 catalysts in a continuous fixed-bed reactor. The conversions of $\mathrm{CH}_{4}$ are summarized in Figure 8. The Mo/HMCM-22 catalysts reveal a volcano curve for the $\mathrm{CH}_{4}$ conversions, with increasing the distance between the Mo species and HMCM-22 zeolite. Moreover, the Mo/HMCM22-MM catalyst exhibited a better $\mathrm{CH}_{4}$ conversion than the other catalysts. The product selectivities of the MDA process were also compared in Figure 8. The Mo/HMCM-22-HS and $\mathrm{Mo} / \mathrm{HMCM}-22-\mathrm{DCB}$ display rather low selectivity to benzene, but high selectivity to coke and other by-products. Compared with the Mo/HMCM-22-HS and Mo/HMCM22-DCB catalysts, the Mo/HMCM-22-WI and Mo/HMCM-22-PM remarkably improved the benzene selectivity. However, they still exhibit high coke selectivity. Among these Mo/HMCM-22 catalysts, the Mo/HMCM-22-MM exhibits the highest selectivity to benzene, while the lowest selectivity to coke. The benzene selectivity reached $64.3 \%$, and the coke selectivity was only $18.1 \%$. 


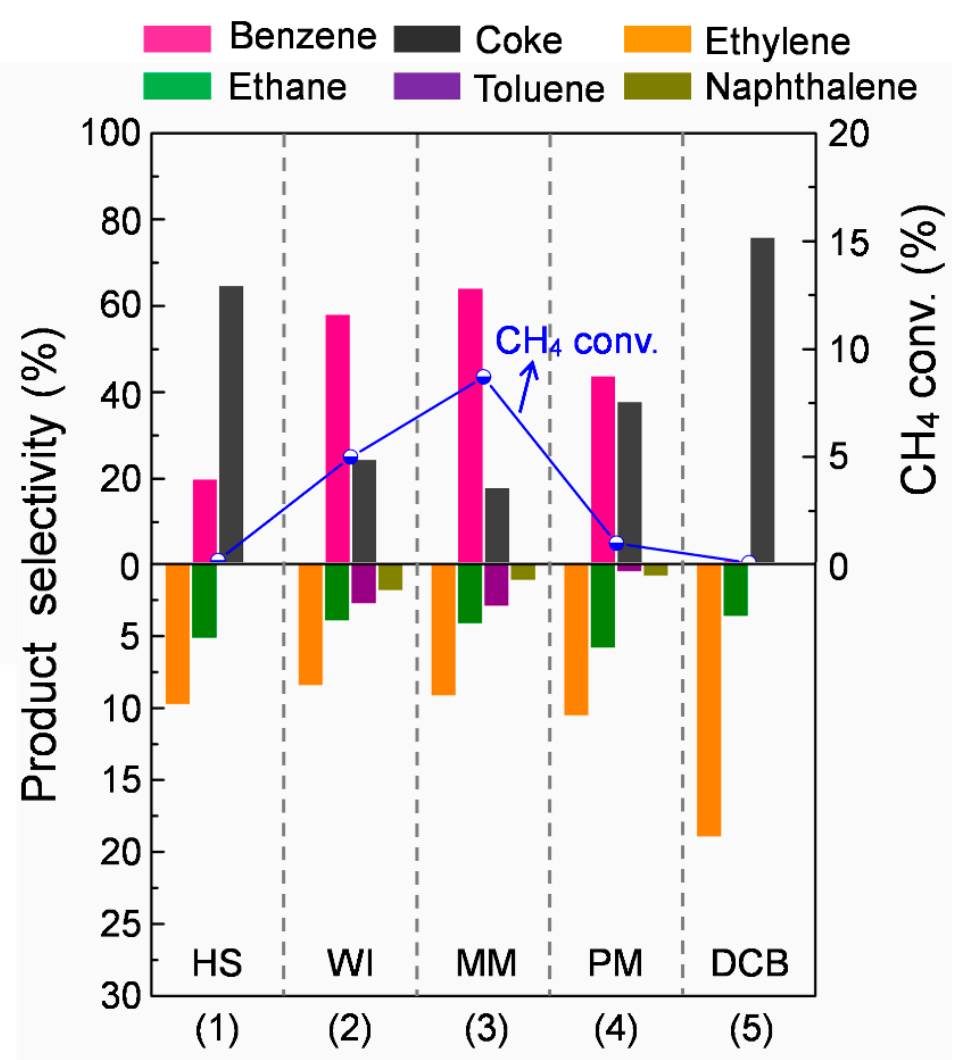

Figure 8. MDA performance of the Mo/HMCM-22 catalysts. (1) Mo/HMCM-22-HS; (2) Mo/HMCM22-WI; (3) Mo/HMCM-22-MM; (4) Mo/HMCM-22-PM and (5) Mo/HMCM-22-DCB. They are also abbreviated as HS, WI, MM, PM, and DCB in the figure, respectively. Reaction condition: temperature, $700{ }^{\circ} \mathrm{C}$; pressure, $1 \mathrm{~atm} ; \mathrm{CH}_{4} / \mathrm{Ar}=9 / 1$; flow rate, $12.5 \mathrm{~mL} \mathrm{~min}^{-1}$; catalyst weight, $0.5 \mathrm{~g}$; and time on stream, $6 \mathrm{~h}$.

According to the characterization results, we demonstrated that the Mo/HMCM-22 catalysts possessed similar Mo contents, $\mathrm{Si} / \mathrm{Al}$ ratios, zeolite crystals and porous structures (Figures 2 and 4; Tables 1 and S2). Moreover, we further proved that the Mo/HMCM-22-WI and Mo/HMCM-22-MM catalysts also formed similar acid properties and surface chemical states (Figures 6 and 7). Therefore, although the $\mathrm{CH}_{4}$ conversion can be affected by Mo species or tuning the distance between the Mo species and HMCM-22 zeolite, the benzene and coke selectivity should remain unchanged over these Mo/HMCM-22 catalysts. Unexpectedly, the Mo/HMCM-22-MM catalyst generated higher benzene selectivity and lower coke selectivity than all the other Mo/HMCM-22 catalysts, including the Mo/HMCM-22WI catalyst. It indicates that a medium distance between the Mo species and HMCM-22 zeolite promoted the benzene formation, and inhibited the carbon deposition.

In contrast, the Mo/HMCM-22-HS and Mo/HMCM-22-WI catalysts generated low selectivity of benzene and high selectivity of coke in the MDA process; this was mainly due to the short distance between the Mo species and HMCM-22 zeolite. The short diffusion distance could accelerate excessive secondary reactions in the HMCM-22 zeolite, resulting in the heavy carbon deposition on the zeolite. The Mo/HMCM-22-PM and Mo/HMCM22-DCB catalysts also produced the low selectivity of benzene and high selectivity of coke. These phenomena should be attributed to the long distance between the Mo species and HMCM-22 zeolite. The long diffusion distance would suppress aromatization of the intermediates on the HMCM-22 zeolite. Ultimately, the high selectivity of coke was caused by methane decomposition on the Mo species.

After the MDA process, we further characterized the spent Mo/HMCM-22 catalysts by SEM, TG and Raman analyses. The SEM images revealed that surface morphologies of the spent catalysts were the same as those of the fresh catalysts as in Figure 3 and Figure S3. 
The TG analysis uncovered that a high mass loss appeared at a temperature range from 450 to $640^{\circ} \mathrm{C}$ over the Mo/HMCM-22-WI as in Figure S4; it should be ascribed to removal of the deposited carbon [42,43]. The Mo/HMCM-22-MM also exhibited a high mass loss due to the deposited carbon, owing to its high $\mathrm{CH}_{4}$ conversion. The Mo/HMCM-22-HS and Mo/HMCM-22-PM showed low mass loss for the deposited carbon, because of their low $\mathrm{CH}_{4}$ conversion. We further utilized the Raman analysis to investigate the deposited carbon on the Mo/HMCM-22-WI and Mo/HMCM-22-MM as in Figure S5. The results unveiled that the Mo/HMCM-22-WI generated disordered and graphitic carbon species, but Mo/HMCM-22-MM mainly formed the graphitic carbon species [44,45]. This implies that Mo/HMCM-22-MM successfully mitigated the deposition of disordered carbon species. Hence, it exhibited a low selectivity to coke in the MDA process.

\section{Materials and Methods}

\subsection{Catalyst Preparation}

Na-form MCM-22 zeolite $(\mathrm{Si} / \mathrm{Al}=20)$ was prepared via hydrothermal synthesis. In brief, 24.88 g colloidal silica (LUDOX ${ }^{\circledR}$ SM colloidal silica $30 \mathrm{wt} \%$ suspension in $\mathrm{H}_{2} \mathrm{O}$; SigmaAldrich Co., LLC., St. Louis, MO, USA) and $0.84 \mathrm{~g} \mathrm{NaAlO}_{2}\left(31 \sim 35 \% \mathrm{Na}_{2} \mathrm{O}, 34 \sim 39 \% \mathrm{Al}_{2} \mathrm{O}_{3}\right.$; Kanto Chemical Co., Inc., Tokyo, Japan) were dissolved in deionized water (13.65 mL), respectively. The two solutions were stirred at room temperature for $24 \mathrm{~h}$, and then mixed together in a beaker. After mixing the two solutions, $0.14 \mathrm{~g} \mathrm{NaOH}(\geq 98 \%$, FUJIFILM Wako Pure Chemical Corporation, Osaka, Japan) and $8.88 \mathrm{~g}$ hexamethyleneimine (HMI, 99\%, Sigma-Aldrich Co., LLC., St. Louis, MO, USA) were also added into the beaker. After vigorously stirring the mixture for $4 \mathrm{~h}$, we obtained a precursor sol with molar composition of $1.0 \mathrm{SiO}_{2}: 0.025 \mathrm{Al}_{2} \mathrm{O}_{3}: 0.05 \mathrm{Na}_{2} \mathrm{O}: 0.50 \mathrm{HMI}: 20 \mathrm{H}_{2} \mathrm{O}$. Furthermore, the precursor sol was transferred into a Teflon-lined autoclave, for hydrothermal synthesis at $150{ }^{\circ} \mathrm{C}$ for 5 days with a rotation speed of $10 \mathrm{rpm}$. The solid product after the hydrothermal synthesis was centrifuged, washed with deionized water, and dried at $120^{\circ} \mathrm{C}$ overnight. The dried product was further calcined in air at $550^{\circ} \mathrm{C}$ for $6 \mathrm{~h}$. The Na-form MCM-22 zeolite was obtained after the calcination.

To obtain H-form MCM-22 zeolite, that is, HMCM-22, the Na-form MCM-22 zeolite was treated using a conventional ion-exchange method. Typically, the Na-form MCM-22 zeolite $(3.0 \mathrm{~g})$ was added into an aqueous solution of $\mathrm{NH}_{4} \mathrm{NO}_{3}\left(1.0 \mathrm{~mol} \mathrm{~L}^{-1} ; 50 \mathrm{~mL}\right)$. The suspension was stirred at $80^{\circ} \mathrm{C}$ for $8 \mathrm{~h}$. Then the solid product was centrifuged, dried at $120^{\circ} \mathrm{C}$ overnight and calcined at $550{ }^{\circ} \mathrm{C}$ for $6 \mathrm{~h}$. The HMCM-22 zeolite was formed by repeating these ion-exchange procedures for 3 times.

Mo/HMCM-22-HS catalyst was also prepared via hydrothermal synthesis. During the synthesis, $\mathrm{MoO}_{3}(0.49 \mathrm{~g}$, 100nm power, Sigma-Aldrich Co., LLC., St. Louis, MO, USA), $\mathrm{NaOH}(0.14 \mathrm{~g})$ and HMI ( $8.88 \mathrm{~g})$ were simultaneously introduced into the mixture, to produce the precursor sol. The other preparation processes were the same as those of the HMCM-22 sample. We labeled this catalyst as Mo/HMCM-22-HS.

Mo/HMCM-22-WI catalyst was synthesized using a method of wet impregnation. In the preparation, $0.24 \mathrm{~g}\left(\mathrm{NH}_{4}\right)_{6} \mathrm{Mo}_{7} \mathrm{O}_{24} \cdot 4 \mathrm{H}_{2} \mathrm{O}$ (FUJIFILM Wako Pure Chemical Corporation, Osaka, Japan) was added into a beaker with deionized water $(4.0 \mathrm{~mL})$. Then, the solution was dripped onto the HMCM-22 zeolite $(2.0 \mathrm{~g})$, followed by ultrasound treatment for $0.5 \mathrm{~h}$ and vacuum drying at $60{ }^{\circ} \mathrm{C}$ overnight. The solid product was further calcined in air at $500{ }^{\circ} \mathrm{C}$ for $6 \mathrm{~h}$. We obtained the Mo/HMCM-22-WI after the calcination.

Mo/HMCM-22-MM catalyst was fabricated by mechanical milling in a mortar grinder (ANM 1000, Nitto Kagaku CO., Ltd., Nagoya, Japan). In the fabrication, $\mathrm{MoO}_{3}(0.20 \mathrm{~g}$ ) and HMCM-22 (2.0 g) were mixed in the mortar, and the mixture was mechanically milled at room temperature for $0.5 \mathrm{~h}$. The resulting product was further calcined in air at $500{ }^{\circ} \mathrm{C}$ for $6 \mathrm{~h}$, to produce the Mo/HMCM-22-MM catalyst.

Mo/HMCM-22-PM catalyst was prepared via physically mixing the $\mathrm{MoO}_{3}$ particles with HMCM-22 zeolite. For this preparation, $\mathrm{MoO}_{3}$ particles (0.05 g; 20 40 mesh) and HMCM-22 zeolite ( $0.45 \mathrm{~g} ; 20 \sim 40$ mesh) were directly mixed before the MDA reaction. In 
addition, Mo/HMCM-22-DCB catalyst was designed in a quartz reactor by using dual catalytic beds for the MDA reaction. The HMCM-22 zeolite particles (0.45 g; 20 40 mesh) were first loaded into the reactor, and then the $\mathrm{MoO}_{3}$ particles (0.05 g; 20 40 mesh) were added on the upper floor of the reactor. The quartz wool, in the middle of the reactor, was employed to control the distance of the $\mathrm{MoO}_{3}$ particles and HMCM-22 zeolite.

\subsection{Catalyst Characterization}

The X-ray diffraction (XRD) patterns were recorded on a Rigaku RINT 2400 X-ray diffractometer (Rigaku, Nagoya, Japan) with $\mathrm{Cu} \mathrm{K} \alpha$ radiation (40 kV and $40 \mathrm{~mA}$ ) at a scanning speed of $2^{\circ} \mathrm{min}^{-1}$ and step size of $0.02^{\circ}(2 \theta)$. The surface morphologies and Mo contents of Mo/HMCM-22 catalysts were analyzed via scanning electron microscopy (SEM, JEOL JSM-6360LV, JEOL Ltd., Tokyo, Japan), and energy dispersive spectrometry (EDS, JED-2300, JEOL Ltd., Tokyo, Japan), respectively. Before the observation, the samples were pretreated in vacuum at $70{ }^{\circ} \mathrm{C}$ for $10 \mathrm{~h}$, and then coated by a platinum layer. The Si/Al ratios of $\mathrm{Mo} / \mathrm{HMCM}-22$ catalysts were determined by wave-dispersive $\mathrm{X}$-ray fluorescence (XRF) spectrometry (PW 2404 R, Philips Japan Co., Ltd., Tokyo, Japan). The nitrogen $\left(\mathrm{N}_{2}\right)$ physisorption was performed via a NOVA2200e analyzer (Micromeritics Japan G.K., Chiba, Japan). Before the analysis, the sample $(80 \mathrm{mg})$ was degassed at $220{ }^{\circ} \mathrm{C}$ for $2 \mathrm{~h}$. The specific surface area was calculated according to the method of Brunauer-Emmett-Teller (BET). The X-ray photoelectron spectroscopy (XPS) analysis was carried out on a Thermo ESCALAB 250Xi X-ray photoelectron spectrometer (Thermo Fisher Scientific Co., Ltd., Tokyo, Japan). The X-ray source was $\mathrm{Al} \mathrm{K} \alpha$ monochromatized radiation (1486.6 eV). The Raman spectra of the spent catalysts were recorded using a Renishaw inVia 2000 Raman microscope (Argon ion laser; excitation wavelength: $514.5 \mathrm{~nm}$, Renishaw, Nagoya, Japan). The thermogravimetric analysis was performed by a TA-60WS thermal analyzer (Shimadzu, Kyoto, Japan). In the analysis, the spent catalyst was heated under a air flow (50 $\left.\mathrm{mL} \mathrm{min}^{-1}\right)$, and the treatment temperature was raised from room temperature to $800{ }^{\circ} \mathrm{C}\left(10^{\circ} \mathrm{C} \min ^{-1}\right)$.

The temperature-programmed reduction of hydrogen $\left(\mathrm{H}_{2}\right.$-TPR) was conducted on a BELCAT-B-TT analyzer (MicrotracBEL Corp., Osaka, Japan). The Mo/HMCM-22 sample (50 mg) was added into a quartz reactor, and the sample was pretreated at $150{ }^{\circ} \mathrm{C}$ for $2 \mathrm{~h}$ with He gas $\left(30 \mathrm{~mL} \mathrm{~min}{ }^{-1}\right)$. Then, the temperature was lowered from 150 to $50{ }^{\circ} \mathrm{C}$, and $\mathrm{H}_{2}$ / Ar gas (5 vol.\% $\mathrm{H}_{2} ; 30 \mathrm{~mL} \mathrm{~min}^{-1}$ ) was introduced into the reactor. The $\mathrm{H}_{2}-\mathrm{TPR}$ profile was recorded using a thermal conductivity detector (TCD) and the temperature was raised to $1000{ }^{\circ} \mathrm{C}\left(10{ }^{\circ} \mathrm{C} \mathrm{min}^{-1}\right)$. The temperature-programmed desorption of ammonia $\left(\mathrm{NH}_{3}-\mathrm{TPD}\right.$ ) was also conducted on the BELCAT-B-TT analyzer (MicrotracBEL Corp., Osaka, Japan). The sample (50 mg) was added into the reactor, and pretreated at $150{ }^{\circ} \mathrm{C}$ for $2 \mathrm{~h}$ with $\mathrm{He}$ gas $\left(30 \mathrm{~mL} \mathrm{~min}^{-1}\right)$. The adsorption of $\mathrm{NH}_{3}$ was conducted at $80{ }^{\circ} \mathrm{C}$ in a $\mathrm{NH}_{3} / \mathrm{He}$ gas $\left(5\right.$ vol. $\left.\% \mathrm{NH}_{3}\right)$ for $1 \mathrm{~h}$. The $\mathrm{NH}_{3}$-TPD profiles were recorded in a He flow $\left(30 \mathrm{~mL} \mathrm{~min}^{-1}\right)$ by raising the temperature to $600{ }^{\circ} \mathrm{C}\left(10^{\circ} \mathrm{C} \mathrm{min}^{-1}\right)$.

\subsection{Catalyst Evaluation}

The MDA reaction was carried out in a continuous fixed-bed reactor at $700{ }^{\circ} \mathrm{C}$ and atmospheric pressure. Typically, $0.5 \mathrm{~g}$ Mo/HMCM-22 catalyst (20 40 mesh) was mixed with $1 \mathrm{~mL}$ of quartz sand, and loaded into a quartz reactor (inner diameter $=8.0 \mathrm{~mm}$ ). Quartz wool plugs were employed to immobilize the catalyst bed, and control the distance of Mo species and HMCM-22 zeolite. Before the reaction, the catalyst was heated to $700{ }^{\circ} \mathrm{C}$ $\left(10^{\circ} \mathrm{C} \mathrm{min}{ }^{-1}\right)$ in an $\mathrm{N}_{2}$ flow $\left(30 \mathrm{~mL} \mathrm{~min}^{-1}\right)$. Then, a gas mixture of $\mathrm{CH}_{4} / \mathrm{Ar}\left(\mathrm{CH}_{4} / \mathrm{Ar}=9 / 1\right.$; $12.5 \mathrm{~mL} \mathrm{~min}^{-1}$; WHSV $=1500 \mathrm{~mL} \mathrm{~h}^{-1} \mathrm{gcat}^{-1}$ ) was introduced into the reactor, to start the reaction. Ar gas was used as an internal standard for calculation of methane conversion and aromatics selectivity. The effluent gas from the reactor to gas chromatograph (GC) was heated on $200{ }^{\circ} \mathrm{C}$, to prevent possible condensation of heavy hydrocarbon products. The effluent gas of $\mathrm{Ar}, \mathrm{CO}, \mathrm{CH}_{4}$, and $\mathrm{CO}_{2}$ were detected by an online GC (Thermal conductivity detector (TCD); Shimadzu GC-8A, Kyoto, Japan) with an activated carbon column. The light hydrocarbons, for example, methane, ethylene and ethane, were analyzed by another 
online GC (Flame ionization detector (FID); Shimadzu GC-2014, Kyoto, Japan) with a Porapak-Q column. The heavy hydrocarbons, such as benzene, toluene, naphthalene, were collected in an ice trap, and analyzed by an off-line GC (Flame ionization detector (FID); Shimadzu GC-2014, Kyoto, Japan) with a capillary column (DB-1). The methane conversion and product selectivity were calculated as follows:

$$
\mathrm{CH}_{4} \text { conv. }(\%)=\left(\mathrm{CH}_{4, \text { in }} / \mathrm{Ar}_{\text {in }}-\mathrm{CH}_{4, \text { out }} / \mathrm{Ar}_{\mathrm{out}}\right) /\left(\mathrm{CH}_{4, \text { in }} / \mathrm{Ar}_{\text {in }}\right) \times 100
$$

$\mathrm{CH}_{4}$ conv.- $\mathrm{CH}_{4}$ conversion; $\mathrm{CH}_{4}$, in - peak area of $\mathrm{CH}_{4}$ in feed gas; $\mathrm{Ar}_{\text {in }}$-peak area of $\mathrm{Ar}$ in feed gas; $\mathrm{CH}_{4}$, out - peak area of $\mathrm{CH}_{4}$ in effluent gas; $\mathrm{Ar}_{\text {out }}$ - peak area of $\mathrm{Ar}$ in effluent gas.

$$
\mathrm{S}_{\mathrm{CxHy}}(\%)=\left(x \times \mathrm{n}_{\mathrm{CxHy}}\right) /\left(\mathrm{n}_{\mathrm{CH} 4, \text { in }}-\mathrm{n}_{\mathrm{CH} 4, \text { out }}\right) \times 100
$$

$\mathrm{S}_{\mathrm{CxHy}}$ - selectivity of product $\mathrm{C}_{\mathrm{x}} \mathrm{H}_{\mathrm{y}} ; x$ - carbon number of product $\mathrm{C}_{\mathrm{x}} \mathrm{H}_{\mathrm{y}} ; \mathrm{n}_{\mathrm{CxHy}}$ mole number of product $\mathrm{C}_{\mathrm{x}} \mathrm{H}_{\mathrm{y}} ; \mathrm{n}_{\mathrm{CH} 4}$, in - mole number of $\mathrm{CH}_{4}$ in feed gas; $\mathrm{n}_{\mathrm{CH} 4 \text {, out }}$-mole number of $\mathrm{CH}_{4}$ in effluent gas.

\section{Conclusions}

In conclusion, a series of Mo/HMCM-22 catalysts with different spatial distances between the Mo species and HMCM-22 zeolite were designed for the methane dehydroaromatization (MDA) process. The methods and strategies of hydrothermal synthesis (HS), wet impregnation (WI), mechanical milling (MM), physical mixing (PM) and dual catalytic beds (DCB) were employed to control the spatial distances. The characterization results demonstrated that these Mo/HMCM-22 catalysts possessed similar Mo contents, Si / Al ratios, zeolite crystals and porous structures. The Mo/HMCM-22-WI and Mo/HMCM22-MM catalysts further generated the same acid properties and surface chemical states. The MDA performance revealed that the Mo/HMCM-22-MM catalyst realized higher $\mathrm{CH}_{4}$ conversion and benzene selectivity, than all the other Mo/HMCM-22 catalysts. More importantly, it significantly decreased coke selectivity in the MDA process. Based on these results and observations, we confirmed that a suitable spatial distance of Mo species and acidic sites over HMCM-22 zeolite can enhance benzene formation and inhibit carbon deposition in the MDA process.

Supplementary Materials: The following are available online at https:/ / www.mdpi.com/2073-434 4/11/2/148/s1.

Author Contributions: The idea was conceived by N.T., X.P. and Y.Z.; Y.Z. performed the experiments and drafted the paper under the supervision of X.P.; A.K., P.Z., J.L., J.F., L.X., C.W., and G.Y. helped to collect and analyze some characterization data. The manuscript was revised and checked through the comments of all authors. All authors have read and agreed to the published version of the manuscript.

Funding: This research received no external funding.

Data Availability Statement: Data is contained within the article.

Conflicts of Interest: The authors declare no conflict of interest.

\section{References}

1. Petrov, A.; Ferri, D.; Krumeich, F.; Nachtegaal, M.; Bokhoven, J.; Kröcher, O. Stable complete methane oxidation over palladium based zeolite catalysts. Nat. Commun. 2018, 9, 2545. [CrossRef]

2. Zhang, Y.; Jiang, H. A novel route to improve methane aromatization by using a simple composite catalyst. Chem. Commun. 2018, 54, 10343-10346. [CrossRef]

3. Agarwal, N.; Freakley, S.; McVicker, R.; Althahban, M.; Dimitratos, N.; He, Q.; Morgan, D.; Jenkins, R.; Willock, D.; Taylor, S.; et al. Aqueous $\mathrm{Au}-\mathrm{Pd}$ colloids catalyze selective $\mathrm{CH}_{4}$ oxidation to $\mathrm{CH}_{3} \mathrm{OH}$ with $\mathrm{O}_{2}$ under mild conditions. Science 2017, 358, $223-227$. [CrossRef] [PubMed]

4. He, Y.; Luan, C.; Fang, Y.; Feng, X.; Peng, X.; Yang, G.; Tsubaki, N. Low-temperature direct conversion of methane to methanol over carbon materials supported Pd-Au nanoparticles. Catal. Today 2020, 339, 48-53. [CrossRef] 
5. Gorin, E.; Fontana, C.; Kidder, G. Chlorination of methane with copper chloride melts rate of chlorination. Ind. Eng. Chem. 1948, 40, 2128-2134. [CrossRef]

6. McBee, E.; Hass, H.; Neher, C.; Strickland, H. Chlorination of methane. Ind. Eng. Chem. 1942, 34, 296-300. [CrossRef]

7. Schwach, P.; Pan, X.; Bao, X. Direct conversion of methane to value-added chemicals over heterogeneous catalysts: Challenges and prospects. Chem. Rev. 2017, 117, 8497-8520. [CrossRef] [PubMed]

8. Guo, X.; Fang, G.; Li, G.; Ma, H.; Fan, H.; Yu, L.; Ma, C.; Wu, X.; Deng, D.; Wei, M.; et al. Direct, nonoxidative conversion of methane to ethylene, aromatics, and hydrogen. Science 2014, 344, 616-619. [CrossRef]

9. Morejudo, S.; Zanón, R.; Escolástico, S.; Yuste-Tirados, I.; Malerød-Fjeld, H.; Vestre, P.; Coors, W.; Martínez, A.; Norby, T.; Serra, J.; et al. Direct conversion of methane to aromatics in a catalytic co-ionic membrane reactor. Science 2016, 353, 563-566. [CrossRef]

10. Behrens, M.; Studt, F.; Kasatkin, I.; Kühl, S.; Hävecker, M.; Abild-Pedersen, F.; Zander, S.; Girgsdies, F.; Kurr, P.; Kniep, B.; et al. The active site of methanol synthesis over $\mathrm{Cu} / \mathrm{ZnO} / \mathrm{Al}_{2} \mathrm{O}_{3}$ industrial catalysts. Science 2012, 336, 893-897. [CrossRef]

11. Tan, L.; Zhang, P.; Suzuki, Y.; Li, H.; Guo, L.; Yoneyama, Y.; Chen, J.; Peng, X.; Tsubaki, N. Bifunctional capsule catalyst of $\mathrm{Al}_{2} \mathrm{O}_{3} @ \mathrm{Cu}$ with strengthened dehydration reaction field for direct synthesis of dimethyl ether from syngas. Ind. Eng. Chem. Res. 2019, 58, 22905-22911. [CrossRef]

12. Li, J.; He, Y.; Tan, L.; Zhang, P.; Peng, X.; Oruganti, A.; Yang, G.; Abe, H.; Wang, Y.; Tsubaki, N. Integrated tuneable synthesis of liquid fuels via Fischer-Tropsch technology. Nat. Catal. 2018, 1, 787-793. [CrossRef]

13. Wei, Q.; Li, H.; Liu, G.; He, Y.; Wang, Y.; Tan, Y.; Wang, D.; Peng, X.; Yang, G.; Tsubaki, N. Metal 3D printing technology for functional integration of catalytic system. Nat. Commun. 2020, 11, 4098. [CrossRef] [PubMed]

14. Wang, L.; Tao, L.; Xie, M.; Xu, G.; Huang, J.; Xu, Y. Dehydrogenation and aromatization of methane under non-oxidizing conditions. Catal. Lett. 1993, 21, 35-41. [CrossRef]

15. Ma, D.; Shu, Y.; Cheng, M.; Xu, Y.; Bao, X. On the induction period of methane aromatization over Mo-based catalysts. J. Catal. 2000, 194, 105-114. [CrossRef]

16. Spivey, J.; Hutchings, G. Catalytic aromatization of methane. Chem. Soc. Rev. 2014, 43, 792-803. [CrossRef]

17. Ma, D.; Wang, D.; Su, L.; Shu, Y.; Xu, Y.; Bao, X. Carbonaceous deposition on Mo/HMCM-22 catalysts for methane aromatization: A TP technique investigation. J. Catal. 2002, 208, 260-269. [CrossRef]

18. Ismagilov, Z.; Matus, E.; Tsikoza, L. Direct conversion of methane on Mo/ZSM-5 catalysts to produce benzene and hydrogen: Achievements and perspectives. Energy Environ. Sci. 2008, 1, 526-541. [CrossRef]

19. Tang, P.; Zhu, Q.; Wu, Z.; Ma, D. Methane activation: The past and future. Energy Environ. Sci. 2014, 7, 2580-2591. [CrossRef]

20. Bao, J.; He, J.; Zhang, Y.; Yoneyama, Y.; Tsubaki, N. A Core/Shell catalyst produces a spatially confined effect and shape selectivity in a consecutive reaction. Angew. Chem. 2007, 47, 353-356. [CrossRef]

21. Yang, G.; Tsubaki, N.; Shamoto, J.; Yoneyama, Y.; Zhang, Y. Confinement effect and synergistic function of H-ZSM-5/Cu-ZnO$\mathrm{Al}_{2} \mathrm{O}_{3}$ capsule catalyst for one-step controlled synthesis. J. Am. Chem. Soc. 2010, 132, 8129-8136. [CrossRef] [PubMed]

22. Yang, G.; Tan, Y.; Han, Y.; Qiu, J.; Tsubaki, N. Increasing the shell thickness by controlling the core size of zeolite capsule catalyst: Application in iso-paraffin direct synthesis. Catal. Commun. 2008, 9, 2520-2524. [CrossRef]

23. Yamane, N.; Wang, Y.; Li, J.; He, Y.; Zhang, P.; Nguyen, L.; Tan, L.; Ai, P.; Peng, X.; Wang, Y.; et al. Building premium secondary reaction field with a miniaturized capsule catalyst to realize efficient synthesis of a liquid fuel directly from syngas. Catal. Sci. Technol. 2017, 7, 1996-2000. [CrossRef]

24. Jiao, F.; Li, J.; Pan, X.; Xiao, J.; Li, H.; Ma, H.; Wei, M.; Pan, Y.; Zhou, Z.; Li, M.; et al. Selective conversion of syngas to light olefins. Science 2016, 351, 1065-1068. [CrossRef] [PubMed]

25. Wang, Y.; Tan, L.; Tan, M.; Zhang, P.; Fang, Y.; Yoneyama, Y.; Yang, G.; Tsubaiki, N. Rationally designing bifunctional catalysts as an efficient strategy to boost $\mathrm{CO}_{2}$ hydrogenation producing value-added aromatics. ACS Catal. 2019, 9, 895-901. [CrossRef]

26. Cheng, K.; Zhou, W.; Kang, J.; He, S.; Shi, S.; Zhang, Q.; Pan, Y.; Wen, W.; Wang, Y. Bifunctional catalysts for one-step conversion of syngas into aromatics with excellent selectivity and stability. Chem 2017, 3, 334-347. [CrossRef]

27. Miao, D.; Ding, Y.; Yu, T.; Li, J.; Pan, X.; Bao, X. Selective synthesis of benzene, toluene, and xylenes from syngas. ACS Catal. 2020, 10, 7389-7397. [CrossRef]

28. Zhou, C.; Shi, J.; Zhou, W.; Cheng, K.; Zhang, Q.; Kang, J.; Wang, Y. Highly active ZnO-ZrO 2 aerogels integrated with H-ZSM-5 for aromatics synthesis from carbon dioxide. ACS Catal. 2020, 10, 302-310. [CrossRef]

29. Razzaq, M.; Zeeshan, M.; Qaisar, S.; Iftikhar, H.; Muneer, B. Investigating use of metal-modified HZSM-5 catalyst to upgrade liquid yield in co-pyrolysis of wheat straw and polystyrene. Fuel 2019, 257, 116-119. [CrossRef]

30. Abedin, M.; Kanitkar, S.; Bhattar, S.; Spivey, J. Methane dehydroaromatization using Mo supported on sulfated zirconia catalyst: Effect of promoters. Catal. Today 2020, in press. [CrossRef]

31. Balyan, S.; Haider, A.; Khan, T.; Pant, K. Boric acid treated HZSM-5 for improved catalyst activity in non-oxidative methane dehydroaromatization. Catal. Sci. Technol. 2020, 10, 3857-3867. [CrossRef]

32. Martínez, A.; Peris, E.; Derewinski, M.; Burkat-Dulak, A. Improvement of catalyst stability during methane dehydroaromatization (MDA) on Mo/HZSM-5 comprising intracrystalline mesopores. Catal. Today 2011, 169, 75-84. [CrossRef]

33. Liu, H.; Xu, Y.; Bao, X. Methane dehydroaromatization under nonoxidative conditions over Mo/HZSM-5 catalysts: Identification and preparation of the Mo active species. J. Catal. 2006, 239, 441-450. [CrossRef]

34. Mishra, S.; Haider, M.; Pant, K. Controlling the evolution of active molybdenum carbide by moderating the acidity of Mo/HMCM22 catalyst in methane dehydroaromatization. Catal. Lett. 2020, 150, 3653-3666. [CrossRef] 
35. Katada, N.; Igi, H.; Kim, J.; Niwa, M. Determination of the acidic properties of zeolite by theoretical analysis of temperatureprogrammed desorption of ammonia based on adsorption equilibrium. J. Phys. Chem. B 1997, 101, 5969-5977. [CrossRef]

36. Shu, Y.; Ma, D.; Xu, L.; Xu, Y.; Bao, X. Methane dehydro-aromatization over Mo/MCM-22 catalysts: A highly selective catalyst for the formation of benzene. Catal. Lett. 2000, 70, 67-73. [CrossRef]

37. Song, J.; Ni, X.; Zhang, D.; Zheng, H. Fabrication and photoluminescence properties of hexagonal MoO 3 rods. Solid State Sci. 2006, 8, 1164-1167. [CrossRef]

38. Światowska-Mrowiecka, J.; De Diesbach, S.; Maurice, V.; Zanna, S.; Klein, L.; Briand, E.; Vickridge, I.; Marcus, P. Li-ion intercalation in thermal oxide thin films of $\mathrm{MoO}_{3}$ as studied by XPS, RBS, and NRA. J. Phys. Chem. C 2008, 112, 11050-11058. [CrossRef]

39. Dong, W.; Ham, J.; Jung, G.; Son, J.; Lee, J. Ultrafast laser-assisted synthesis of hydrogenated molybdenum oxides for flexible organic solar cells. J. Mater. Chem. A 2016, 4, 4755-4762. [CrossRef]

40. Kónya, Z.; Vesselényi, I.; Kiss, J.; Farkas, A.; Oszkó, A.; Kiricsi., I. XPS study of multiwall carbon nanotube synthesis on Ni-, V-, and Ni, V-ZSM-5 catalysts. Appl. Catal. A Gen. 2004, 260, 55-61. [CrossRef]

41. Sun, T.; Gong, M.; Cai, Y.; Xiao, S.; Zhang, L.; Zhang, Y.; Xu, Z.; Zhang, D.; Liu, Y.; Zhou, C. MCM-41-supported Fe(Mn)/Cu bimetallic heterogeneous catalysis for enhanced and recyclable photo-Fenton degradation of methylene blue. Res. Chem. Intermediat. 2020, 46, 459-474. [CrossRef]

42. Zhu, P.; Yang, G.; Sun, J.; Fan, R.; Zhang, P.; Yoneyama, Y.; Tsubaki, N. A hollow Mo/HZSM-5 zeolite capsule catalyst: Preparation and enhanced catalytic properties in methane dehydroaromatization. J. Mater. Chem. A 2017, 5, 8599-8607. [CrossRef]

43. Liu, B.; Jiang, L.; Sun, H.; Au, C. XPS, XAES, and TG/DTA characterization of deposited carbon in methane dehydroaromatization over Ga-Mo/ZSM-5 catalyst. Appl. Surf. Sci. 2007, 253, 5092-5100. [CrossRef]

44. Pimenta, M.; Dresselhaus, G.; Dresselhaus, M.; Cancado, L.; Jorio, A.; Saito, R. Studying disorder in graphite-based systems by Raman spectroscopy. Phys. Chem. Chem. Phys. 2007, 9, 1276-1290. [CrossRef]

45. Kudin, K.; Ozbas, B.; Schniepp, H.; Prud'homme, R.; Aksay, I.; Car, R. Raman spectra of graphite oxide and functionalized graphene sheets. Nano Lett. 2008, 8, 36-41. [CrossRef] 